\title{
Active disturbance rejection control of a permanent magnet synchronous generator for wind turbine applications
}

\section{Control por rechazo activo de perturbaciones de un generador síncrono de imanes permanentes para aplicaciones en aerogeneradores}

\author{
AGUILAR-ORDUÑA, Mario Andrés $\dagger^{*} *$ \& SIRA-RAMÍREZ, Hebertt José \\ Centro de Investigación y de Estudios Avanzados del Instituto Politécnico Nacional (CINVESTAV)
}

ID $1^{\text {st }}$ Author: Mario Andrés, Aguilar-Orduña / ORC ID: 0000-0002-0414-3864, CVU CONACYT ID: 702805

ID $1^{\text {st }}$ Co-author: Hebertt José, Sira-Ramírez / ORC ID: 0000-0003-0118-4764, CVU CONACYT ID: 20550

DOI: $10.35429 / J R D .2021 .19 .7 .9 .21$

Received March 27, 2021; Accepted June 30, 2021

\begin{abstract}
With sight on maximizing the amount of energy that can be extracted, by a wind turbine, from the wind, this article solves the maximum power point tracking problem for a permanent magnet synchronous generator-based horizontal wind turbine connected to the electrical grid. A three-phase back-to-back converter, which allows a decoupling between the electrical grid and the generator, is employed as an interphase between the wind turbine and the utility grid. Based on the mathematical model in the synchronous reference frame and taking advantage of the differential flatness property the system exhibits, controllers based on the active disturbance rejection methodology are designed, in this work, to track the curve of maximum extracted power from the wind and manage the generated electricity into the grid. At the same time, the phase angle of the electricity generated is synchronized with the phase angle of the electrical grid. Numerical simulations are performed to support the controllers presented in this work.
\end{abstract}

Wind Turbine, Differential flatness, ADRC

\begin{abstract}
Resumen
Con vistas a maximizar la cantidad de energía que es posible extraer del viento, el presente trabajo resuelve el problema del seguimiento del punto de máxima extracción de potencia, para un aerogenerador de eje horizontal basado en un generador síncrono de imanes permanentes, conectado a la red eléctrica a través de un convertidor trifásico de potencia Back to Back, el cual permite un desacoplo entre el generador síncrono de imanes permanentes y la red eléctrica. Partiendo del modelo matemático en el marco de referencia síncrono, y explotando la propiedad de planitud diferencial que exhibe el sistema, se diseñan esquemas de control basados en la metodología del rechazo activo de perturbaciones, para realizar el seguimiento de la curva de máxima extracción de potencia y regular la energía que se suministra a la red eléctrica. Simultáneamente, se sincroniza la fase de la energía producida por el generador eléctrico con la fase de la red eléctrica. Los desarrollos presentados en este trabajo son respaldados mediante simulaciones numéricas.
\end{abstract}

Aerogenerador, Planitud diferencial, ADRC

Citation: AGUILAR-ORDUÑA, Mario Andrés \& SIRA-RAMÍREZ, Hebertt José. Active disturbance rejection control of a permanent magnet synchronous generator for wind turbine applications. Journal of Research and Development. 2021. 7-19: 9-21

\footnotetext{
* Author Correspondence (mario.aguilaro@ cinvestav.mx).

$\dagger$ Researcher contributing as first author.
} 


\section{Introduction}

Since a long time ago, humanity has been interested in using wind power to ease or solve various tasks and even necessities, such as grain milling and water pumping. When electric power arose, engineers and researchers begin to look at wind power as a powerful energy source apt to drive electric generators. Thus, wind energy started to be used in electric power generation, emerging the first wind turbines.

Nowadays, climate change, the looming shortage of fossil fuels, a growing concern for the environment, and a diversification tendency in the electrical power industry have been driving the evolution of wind turbine technology, as it similarly happened in 1970 when the oil crisis triggered a higher interest and development of wind turbines. The evolution of this technology is such that today the renewable energy with the highest growth in the world is wind energy (Ackermann \& Söder, An overview of wind energy-status 2002, 2002) (Bianchi, de Battista, \& Mantz, 2007).

Various problems and research topics have arisen from the great interest and development around wind energy, most of them focused on maximizing the amount of energy extracted from the wind. Around this problem, researchers and engineers have proposed different solutions. Among others, the proposals range from the entire design of the wind turbine or even the aerodynamic profile of the blades to the electric generator selection in wind turbine construction. In this way, various wind turbine designs have arisen, some of them with fixed or variable pitch angle blades or even blades that can change their aerodynamic profile. Other wind turbine designs consider different electric generator topologies, which can work, either with a fixed or variable angular speed. All focused on extracting the maximum amount of energy from the wind (Ackermann, Wind power in power systems, 2005) (Wu, Lang, Zargari, \& Kouro, 2011).

Consequently, wind turbines are becoming increasingly complex mechatronic systems, which require control designs that guarantee a safe and suitable performance of the whole system and even the interacting subsystems that compound them. Furthermore, those control designs must maximize the amount of energy extracted from the wind.
Recently permanent magnet synchronous generator (PMSG) has been the subject of great interest owing to its high efficiency, construction and, maintenance simplicity, besides its design capacity of integrating a large number of pole pairs, allowing the development of direct driven wind turbines. It's important to consider that PMSGs are not the most employed in the wind turbine market, mainly due to the high cost (which has been decreasing with the development of technology) of permanent magnets needed in their construction.

Due to the number capability of pole pairs of PMSG, direct driven wind turbines can easily prescind of those heavy and complex gearboxes employed to adjust the low angular speed of the blades to match the high angular velocity of the electric generator. The lack of a gearbox reduces the weight of the wind turbine and the number of mechanical elements which require frequent maintenance and are also a source of failures principally due to the changing nature of the wind (Polinder, et al., 2013).

The design of control schemes that maximize the amount of energy extracted from the wind by suitable and safe control of the wind turbine, despite the numerous disturbances and uncertainties that these systems are subject to, plays a relevant role in the evolution of this technology. Many control technics have been used to control wind turbines, such as gain scheduling, optimal control, sliding mode control, to mention a few (Njiri \& Söffker, 2016).

This work presents control schemes based on the Active Disturbance Rejection Control (ADRC). We take advantage of the differential flatness property that the permanent magnet synchronous generator exhibits for this purpose. The maximum power point tracking (MPPT) control task of a horizontal axis wind turbine driven by a PMSG connected to the electrical grid via a three-phase back-to-back converter is solved.

In subsequent sections are presented the mathematical model of the wind turbine, followed by the problem formulation and control objectives. Later on, the differential flatness of the system is found and used to design the control schemes and solve the control objectives previously presented. Numerical simulations test and support the control schemes developed. 
The final sections contain the conclusions and bibliography references.

\section{The dynamic model of a direct-driven horizontal axis wind turbine}

Consider a direct-driven horizontal axis wind turbine based on a PMSG connected to the electric grid via a back-to-back converter, as shown in Figure 1. In these types of wind turbines, the blades rotor is directly coupled to a PMSG constructed with a large number of pole pairs (i.e., without a gearbox). The PMSG is connected to the grid with a Back-to-Back converter.

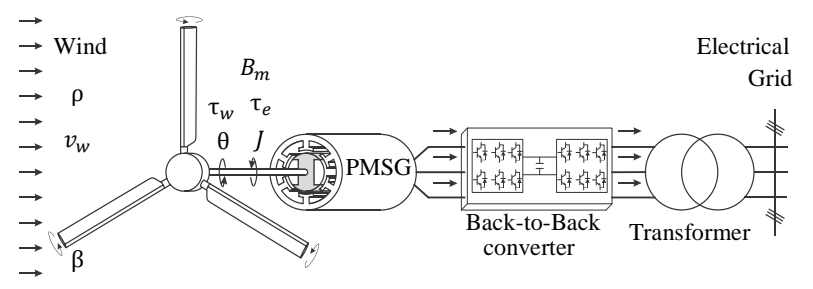

Figure 1 Direct-driven horizontal wind turbine based on a PMSG

Source: Made by the author

To model the system, we divide the wind turbine into three principal subsystems, the blades, the permanent magnet synchronous generator and, the grid side converter which, couples the wind turbine with the electrical grid.

\section{Wind energy extraction}

The blades of a wind turbine are the elements that transform the kinetic energy in the wind into mechanical energy. The power that blades extract from the wind is given by,

$$
P_{w}=\frac{1}{2} \rho A v_{w}^{3} C_{p}\left(\lambda_{t}, \beta\right)
$$

Where $\rho$ is the air density, $A=\pi r_{t}^{2}$ is the area cover by the rotor blades with a radius $r_{t}$, $v_{w}$ is the wind speed and, $C_{p}$ is a power coefficient dependent on the blade aerodynamic design; it's important to say that $C_{p}$ is bounded by 0.593 , known as the Betz limit. This power coefficient is a function of the blades pitch angle $\beta$ and the tip speed ratio $\lambda_{t}$ defined as:

$$
\lambda_{t}=\frac{\omega_{t} r_{t}}{v_{w}}
$$

With $\omega_{t}$ is the rotor's angular velocity. The shaft mechanical torque produced by the wind is given by the equation:

$$
\tau_{w}=\frac{P_{w}}{\omega_{t}}=\frac{1}{2} \rho \pi r_{t}^{3} v_{w}^{2} \frac{C_{p}\left(\lambda_{t}, \beta\right)}{\lambda_{t}}
$$

As we are working with a direct-driven wind turbine, the mechanical equation of the system corresponds to the equation of a single rotating mass:

$$
J \ddot{\theta}+B \dot{\theta}+\tau_{e}=\tau_{w}
$$

$$
\text { Where } \frac{d}{d t} \theta=\dot{\theta}=\omega_{t}, \frac{d^{2}}{d^{2} t} \theta=\ddot{\theta} \text { and } \theta \text { are }
$$
the systems velocity, acceleration, and angular position respectively; $J$ is the inertia momentum of the whole system, $B$ is the systems friction coefficient and $\tau_{e}$ is the electromagnetic torque of the PMSG.

\section{Permanent magnet synchronous generator model}

Consider a round rotor PMSG with sinusoidal flux permanent magnets. It's supposed a star connection in PMSG windings, see Figure 2.
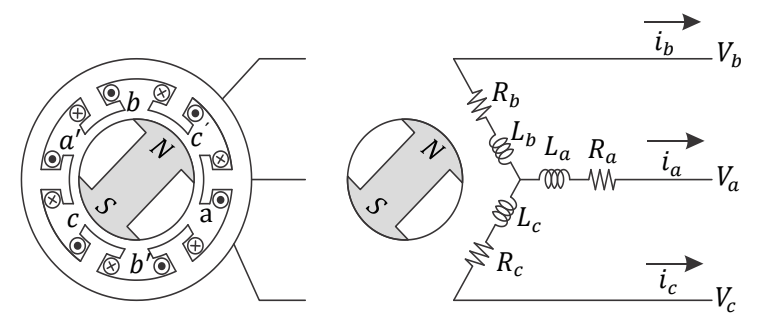

Figure 2 Permanent magnet synchronous generator Source: Made by the author

While we are working with a synchronous machine, the inductances and resistors of the different windings are all nearly of the same value. The dynamic model of the permanent magnet synchronous generator is obtained, in the synchronous (d-q) reference frame, by employing the Clark and Park transformations into the machine electrical equations in the natural $(a-b-c)$ reference frame. By selecting $\theta_{p}=n_{p} \theta$ as the Park angle, the model is:

$$
\begin{aligned}
& v_{d}=R_{s} i_{d}-\frac{3}{2} L_{s} i_{q} n_{p} \frac{d}{d t} \theta+\frac{3}{2} L_{s} \frac{d}{d t} i_{d} \\
& v_{q}=R_{s} i_{q}+\frac{3}{2} L_{s} i_{d} n_{p} \frac{d}{d t} \theta+\frac{3}{2} \kappa \lambda_{0} n_{p} \frac{d}{d t} \theta+ \\
& \frac{3}{2} L_{s} \frac{d}{d t} i_{q}
\end{aligned}
$$

AGUILAR-ORDUÑA, Mario Andrés \& SIRA-RAMÍREZ, Hebertt José. Active disturbance rejection control of a permanent magnet synchronous generator for wind turbine applications. Journal of Research and Development. 2021 


$$
\tau_{e}^{d q}=\frac{n_{p} \lambda_{0}}{\kappa} i_{q}=k_{m} i_{q}
$$

Where $R_{s}$ and $L_{s}$ are the stator inductance and resistance, respectively, $n_{p}$ is the number of pole pairs, $\kappa$ is a Clark transformation scaling factor, and $\lambda_{0}$ is the electromagnetic flux linkages magnitude. The currents $i_{d}$ and $i_{q}$, are the synchronous reference frame electrical currents and, $v_{d}, v_{q}$, are their respective voltages, which are the system control inputs. A three-phase Back-to-Back converter induces those voltages into the PMSG; this work considers the average model of the three-phase Back-to-Back converter. Notice that the angle $\theta$ represents the angular displacement of both the permanent magnet synchronous generator and the wind turbine's rotor since we consider a direct-driven wind turbine.

\section{Model of the grid side converter}

The Back-to-Back converter DC-link and the filter that connects the wind turbine with the electrical grid constitutes the grid side converter (GSC). See Figure 3.

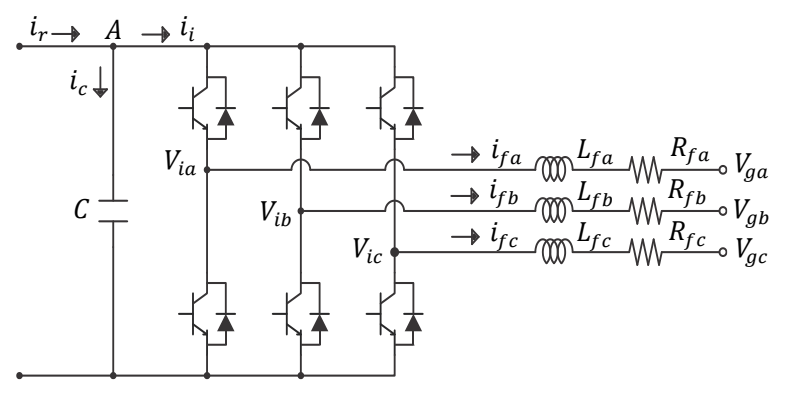

Figure 3: Grid Side Converter with an RL filter Source: Made by the author

Since we are working with a three-phase balanced system, each filter-branch inductance and resistance must have the same value. And supposing a lossless DC-link, whose voltage is given by,

$$
\frac{d}{d t} V_{d c}=\frac{1}{C} i_{c}=\frac{1}{C}\left(i_{r}-i_{i}\right)
$$

By taking the integral of the electrical grid frequency as Parks angle, i.e., $\theta_{p}=\int \omega_{p}$, the dynamic model in the synchronous reference frame of the grid side converter is:

$V_{i d}=R_{f} i_{f d}-L_{f} i_{f q}+L_{f} \frac{d}{d t} i_{f d}+V_{g d}$

$$
\begin{aligned}
& V_{i q}=R_{f} i_{f q}+\omega_{p} L_{f} i_{f d}+L_{f} \frac{d}{d t} i_{f q}+ \\
& V_{g q}
\end{aligned}
$$

The instantaneous active power $P$ and reactive power $Q$ that the system exchanges with the electrical grid, usually defined in the fixed reference frame $\alpha-\beta$ (Akagi, Watanabe, \& Aredes, 2017), can be expressed via the Park transformation in the synchronous reference frame as,

$$
\begin{aligned}
& P=\frac{3}{2}\left(V_{g d} i_{f d}+V_{g q} i_{f q}\right) \\
& Q=\frac{3}{2}\left(V_{g q} i_{f d}-V_{g d} i_{f q}\right)
\end{aligned}
$$

By equating the DC-link power with the instantaneous active power and, considering that the grid is a balanced three-phase system (notice that in this case, the voltage $V_{g q}=0$ ), we obtain the following expressions for the active and reactive instantaneous powers:

$$
\begin{aligned}
& P=\frac{3}{2} V_{g d} i_{f d}=V_{c d} i_{i} \\
& Q=-\frac{3}{2} V_{g d} i_{f q}
\end{aligned}
$$

\section{Problem formulation and control objectives}

The main objective of a wind turbine is the wind's kinetic energy conversion into electrical power. Figure 4 shows four wind-speed dependant work zones where different generation objectives are defined.

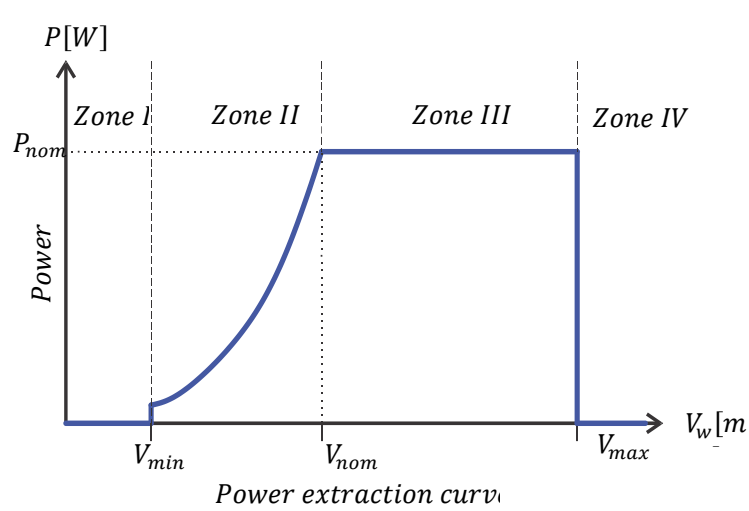

Figure 4 Wind-speed dependent work zones. Source: Made by the author 
Zone I occur when the wind speed is less than the cut-in wind speed, i.e., $v_{w}<v_{\min }$. In this zone, the wind energy is too low to overcome the friction forces and the system's inertia.

In Zone IV, the wind speed exceeds the wind turbine's maximum wind speed limit for a safe operation, i.e., $v_{w}>v_{\max }$. Hence the wind turbine must be stoped to avoid damage or a possible failure of the system. So, in Zones I and IV, it is impossible to extract energy from wind.

At Zone III $\left(v_{\text {nom }}<v_{w}<v_{\max }\right)$, the electric generator must operate at its nominal velocity, so the blades' pitch-angles $\beta$ are adjusted to limit the power extracted from the wind and hence the rotors' angular speed and avoid overcharge.

Zone II corresponds to wind speeds between the cut-in and nominal wind velocity, i.e. $\left(v_{\min }<v_{w}<v_{\text {nom }}\right)$. At this zone, the wind energy is enough to move the wind turbine, but it's not enough to speed up the generator at its nominal speed. Therefore, the generation objective in zone II is to maximize the energy extracted from the wind by adjusting the blades' pitch angle towards $\beta=0$; however, this is not enough while the power coefficient $C_{p}$ is also tip speed ratio dependant. If we can control the angular velocity of the electric generator, then we can regulate the tip speed ratio to an optimal point. And thus extract the maximum amount of energy from the wind. Figure 5 depicts the socalled maximum power curve.

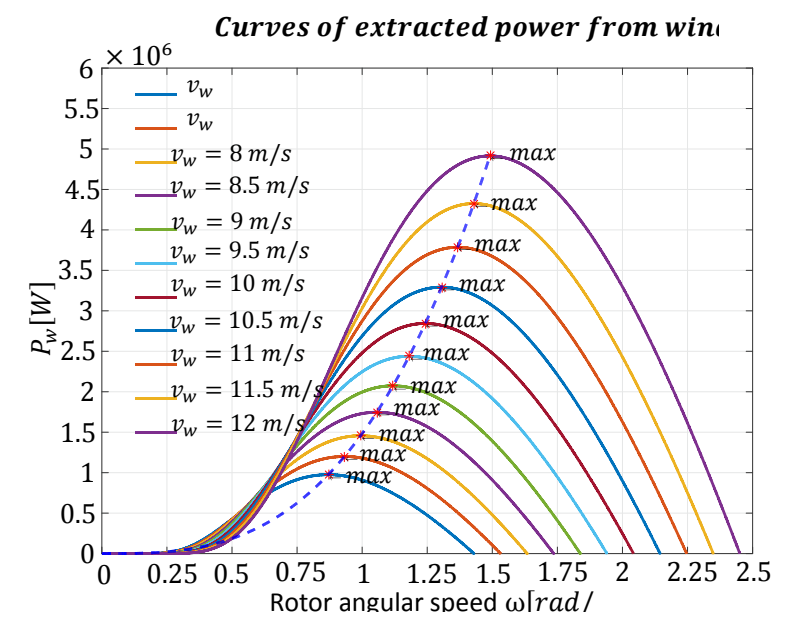

Figure 5 Maximum power curve plot. Source: Made by the author
The above-mentioned reveals the first control objective that is the maximum power curve tracking (MPPT). For this, the desired velocity reference is given by,

$$
\omega_{t, o p t}^{*}=\dot{\theta}_{o p t}=\frac{\lambda_{t, o p t} v_{w}}{r_{t}}
$$

where $\lambda_{t, o p t}$ is the optimum tip speed ratio obtained from the graphs of the power coefficient by setting $\beta=0$. The reference signal is passed through a low pass filter to eliminate the influence of the turbulence and thus avoid excessive stress into the PMSG. From the electric power equation of the PMSG, we can find the term $R_{s}\left(i_{d}^{2}+i_{q}^{2}\right)$, which refers to Joule's losses commonly manifested as heat in the machine. The second control objective is to regulate the current $i_{d}=0$ and thus minimize Joule's losses.

The signals induced by the Back-to-Back converter to either the permanent magnet synchronous generator and the grid filter need an adequate DC-link Voltage. Also, a desirable DClink voltage is required to inject the PMSG active power into the electrical grid. Therefore, the third control objective is to regulate the DClink Voltage $V_{d c}$ toward the desired value $V_{d c}^{*}$.

One of the advantages of employing a Back-to-Back converter is the reactive power regulation capacity, allowing the control of the absorbed or supplied reactive power to the electrical grid. So the fourth control objective is to regulate the reactive power $Q$ towards a reference value $Q^{*}$. Finally, to supply the energy into the electrical grid, the electricity generated by the wind turbine must be synchronized with the electricity in the grid. So the fifth control objective is the synchronization of the electricity between both systems.

\section{Differential flatness}

Differential flatness is a property of dynamic systems that allows parametrizing all system variables (i.e., states, inputs, and outputs) into algebraic-differential expressions in terms of a finite set of independent special-outputs, called flat-outputs. If the above-mentioned happens, the system is called differentially flat. Fliess and his collaborators first introduced this property in (Fliess, Lévine, Martin, \& Rouchon, 1992). 
The differential flatness property is tightly related to the feedback linearization, controllability and, observability concepts. This property trivializes the trajectory planning and is often employed as a tool for analysis purposes of relevant system properties, such as parametrization of the equilibrium point, minimum and non-minimum properties, among others.

It is possible to take advantage of the flatness property and combine it with control schemes such as passivity, optimal control, sliding mode control, active disturbance rejection control, to mention a few (SiraRamírez \& Agrawal, Differentially flat systems, 2004).

\section{Differential flatness of the wind turbine}

The dynamic model of the PMSG in equations (4), (5), (6), and (7) in conjunction with equations (10) and (10) corresponding to the GSC dynamic model, compound the dynamic model of the wind turbine. Notice the four control inputs $v_{d}, v_{q}, V_{i d}$, and $V_{i q}$ of the system. Therefore, we expect to obtain four flat outputs. By inspecting the PMSG equations, we can observe that the control inputs, equations (5) and (6), and the phase variables are parametrizable in terms of the current $i_{d}$, the angular position $\theta$, and their respective derivatives.

$$
\begin{aligned}
& \frac{d}{d t} i_{d}=\left(\frac{2}{3 L_{s}}\right)\left(v_{d}-R_{s} i_{d}-\frac{3}{2} L_{s} i_{q} n_{p} \frac{d}{d t} \theta\right) \\
& \frac{d}{d t} i_{q}=\left[\frac{2}{3 L_{s}}\right]\left[v_{q}-R_{s} i_{q}-\right. \\
& \left.n_{p} \frac{d}{d t} \theta\left(\frac{3}{2} L_{s} i_{d}+\frac{3}{2} \kappa \lambda_{0}\right)\right] \\
& \frac{d^{2}}{d^{2} t} \theta=\left(\frac{1}{J}\right)\left(\tau_{w}-B_{m} \frac{d}{d t} \theta-\frac{n_{p} \lambda_{0}}{\kappa} i_{q}\right) \\
& i_{q}=\left(\frac{\kappa}{n_{p} \lambda_{0}}\right)\left(J \frac{d^{2}}{d^{2} t} \theta-\tau_{w}+B_{m} \frac{d}{d t} \theta\right)
\end{aligned}
$$

Thus, the current $i_{d}$ and the angular position $\theta$ qualifies as the first two flat outputs of the system.

Now, notice that from the grid side converter equations and by employing the relations in (13) and (14), we obtain the following expressions for the phase variables,

$$
\begin{aligned}
& I_{f q}=-\frac{2}{3 V_{g d}} Q \\
& I_{f d}=\frac{2 V_{c d}}{3 V_{g d}}\left(I_{r}-C \frac{d}{d t} V_{c d}\right)
\end{aligned}
$$

Which are expressed in terms of the reactive power $Q$ and the DC-link voltage $V_{c d}$. The same happens with the control inputs in equations (10) and (10). Therefore, $Q$ and $V_{c d}$ qualifies as the second pair of flat-outputs of the system, completing the four expected flatoutputs.

By deriving each one of the flat outputs, we obtain the dynamic model of the PMSG in input-output form as,

$$
\begin{aligned}
& \theta^{(3)}=-\left(\frac{n_{p} \lambda_{0}}{J L_{s}}\right) v_{q}+\left(\frac{1}{J}\right) \dot{\tau}_{m}\left(\frac{n_{p} \lambda_{0}}{J L_{s}}\right)- \\
& \left(R_{s} i_{q}+\frac{3}{2} n_{p} \dot{\theta}\left(L_{s} i_{d}+\kappa \lambda_{0}\right)+B_{m} \ddot{\theta}\right) \\
& \frac{d}{d t} i_{d}=\left(\frac{2}{3 L_{s}}\right) v_{d}+\left(\frac{2}{3 L_{s}}\right)\left(-R_{s} i_{d}-\right. \\
& \left.\frac{3}{2} L_{s} i_{q} n_{p} \frac{d}{d t} \theta\right)
\end{aligned}
$$

And for the GSC we have

$$
\begin{aligned}
& \ddot{V}_{c d}=-\frac{3 V_{g d}}{2 L_{f} V_{d c}} V_{i d}-\frac{3 V_{g d}}{2 V_{d c}}\left(-V_{g d}-\right. \\
& \left.R_{f} I_{f d}+\omega_{p} L_{f} I_{f q}\right)+\frac{\dot{I}_{r}}{C}-\frac{3 \dot{V}_{g d} I_{f d}}{2 V_{c d}}+ \\
& \frac{3 V_{g d} I_{f} \dot{V}_{c d}}{2 V_{c d}^{2}} \\
& \dot{Q}=-\frac{3 V_{g d}}{2 L_{f}} V_{i q}-\frac{3 V_{g d}}{2}\left(-V_{g q}-R_{f} I_{f q}-\right. \\
& \left.\omega_{p} L_{f} I_{f d}\right)-\frac{3}{2} \dot{V}_{g d} I_{f q}
\end{aligned}
$$

\section{Active disturbance rejection control.}

Active disturbance rejection control is a robust control technic, whose main idea is to simplify the description of the system by groping in a time-varying total disturbance term all endogenous and exogenous disturbances affecting the system. For example, the disturbance term can contain unmodeled dynamics, parameters uncertainties, and external influences. Further, the effect of the total disturbance term over the system is estimated and canceled as part of a feedback control law. 
Usually, the control law employed in the ADRC scheme requires complete access to all phase variables. Unfortunately, this knowledge is not always available. Commonly, the design of a suitably extended state observer (ESO) or a reduced-order extended state observer (ROESO) is employed to estimate the phase variables and even the influence of the total disturbance term. Then, a feedback control law is design under the basis of those estimations and subtracting the estimate of the disturbance term to solve the entrusted control task (Sira-Ramírez, LuvianoJuárez, Ramírez-Neria, \& Zurita-Bustamante, 2017).

\section{Permanent magnet synchronous generator angular speed control}

Following the active disturbance rejection methodology, lets consider the input-output model in equation (22), written in simplified form:

$$
\theta^{(3)}=-\left(\frac{n_{p} \lambda_{0}}{J L_{s}}\right) v_{q}+\xi_{\theta}=U_{q}+\xi_{\theta}
$$

Where $U_{q}=-\left(\frac{n_{p} \lambda_{0}}{J L_{s}}\right) v_{q}$ is the control input and $\xi_{\theta}=\left(\frac{1}{J}\right) \dot{\tau}_{m}\left(\frac{n_{p} \lambda_{0}}{J L_{s}}\right)-\left(R_{s} i_{q}+\frac{3}{2} n_{p} \dot{\theta}\left(L_{s} i_{d}+\right.\right.$ $\left.\left.\kappa \lambda_{0}\right)+B_{m} \ddot{\theta}\right)$ the total disturbance term. Writing the simplified system in terms of the tracking error we get,

$$
e_{\theta}^{(3)}=e_{U_{q}}+\xi_{\theta}
$$

Where the tracking error of the angular displacement is $e_{\theta}=\theta-\theta^{*}$ and the control input error is $e_{U_{q}}=U_{q}-U_{q}^{*}$ with $\theta^{*}=\int \dot{\theta}_{o p t}$ and $U_{q}^{*}=\frac{d^{3}}{d t^{3}} \theta^{*}$.

It's worth saying that we suppose that only the control input and the angular position are available for measurement. Thus an extended state observer is designed to estimate the disturbance and the non-measured states. Let's define $e_{\theta}=e_{y_{0}}, \dot{e}_{\theta}=e_{y_{1}}$, and $\ddot{e}_{\theta}=e_{y_{2}}$ so

$$
\begin{aligned}
& \hat{\hat{e}_{y_{0}}}=\widehat{e_{y_{1}}}+\lambda_{3}\left(e_{y_{0}}-\widehat{y_{y_{0}}}\right)=\widehat{e_{y_{1}}}+\lambda_{3} \widetilde{e_{0}} \\
& \hat{e_{y_{1}}}=\widehat{e_{y_{2}}}+\lambda_{2} \widetilde{e_{0}} \\
& \dot{\hat{e}_{y_{2}}}=e_{U_{q}}+z+\lambda_{1} \widetilde{e_{0}} \\
& \dot{z}=\lambda_{0} \widetilde{e_{o}}
\end{aligned}
$$

The terms $\widehat{e_{y_{x}}}$ represents the state error estimations, and $z$ is the total disturbance term estimation. Then, the observer errors are defined by

$$
\begin{aligned}
& \widetilde{e_{0}}=e_{y_{0}}-\widehat{e_{y_{0}}} \\
& \widetilde{e_{1}}=e_{y_{1}}-\widehat{e_{y_{1}}} \\
& \widetilde{e_{2}}=e_{y_{2}}-\widetilde{e_{y_{2}}} \\
& \zeta_{e}=\xi_{\theta}-z
\end{aligned}
$$

Whose dynamics satisfy the following differential equation. By defining $e_{0}^{(x)}=\frac{d^{x}}{d t^{x}} e_{0}$ we have

$$
\widetilde{e_{0}^{(4)}}+\lambda_{3} e_{0}^{\widetilde{(3)}}+\lambda_{2} e_{0}^{\widetilde{(2)}}+\lambda_{1} \widetilde{e_{0}^{(1)}}+\lambda_{0} \widetilde{e_{0}}=\dot{\xi}_{\theta}
$$

The corresponding characteristic polynomial is

$$
s^{4}+\lambda_{3} s^{3}+\lambda_{2} s^{2}+\lambda_{1} s+\lambda_{0}=0
$$

From where, we can observe that to ensure exponential stability of the observer, the set of gain parameters $\lambda_{3}, \lambda_{2}, \lambda_{1}, \lambda_{0}$ must compound a Hurwitz set. For that reason, the gain parameters are computed as:

$$
\begin{aligned}
& \lambda_{0}=\omega_{n}^{4} \\
& \lambda_{1}=4 \zeta \omega_{n}^{3} \\
& \lambda_{2}=4 \zeta^{2} \omega_{n}^{2}+2 \omega_{n}^{2} \\
& \lambda_{3}=4 \zeta \omega_{n}
\end{aligned}
$$

Where the terms $\omega_{n}>0$ and $0<\zeta<1$ are the design parameters of the observer.

Once we computed the phase variables and the total disturbance term estimations, we propose a state estimation-based feedback controller with an additional parameter (the estimate of the total disturbance term) to cancel the influence of the total disturbance term.

$$
U_{q}=U_{q}^{*}-k_{2} \hat{e}_{y}^{(2)}-k_{1} \hat{e}_{y}^{(1)}-k_{0} e_{y}-z
$$

The characteristic polynomial obtained from the closed-loop system is

$$
s^{3}+k_{2} s^{2}+k_{1} s+k_{0}=0
$$


Once again, notice that the proper selection of the gain parameters $k_{2}, k_{2} y k_{0}$ guarantees the exponential stability of the controller. The gain parameters must compound a Hurwitz set, for that reason the gain parameters are computed as:

$$
\begin{aligned}
& k_{0}=p \omega_{n}^{2} \\
& k_{1}=2 \zeta \omega_{n} p+\omega_{n}^{2} \\
& k_{2}=2 \zeta \omega_{n}+p
\end{aligned}
$$

The terms $\omega_{n}>0, p>0$ and $0<\zeta<1$ constitute the controller gain parameters.

\section{Current $i_{d}$ controller}

According to the ADRC methodology, we simplify equation (23) corresponding to the PMSG input-output model for the electric current $i_{d}$,

$$
\frac{d}{d t} i_{d}=\left(\frac{2}{3 L_{s}}\right) v_{d}+\xi_{i d}=U_{d}+\xi_{i_{d}}
$$

Where $U_{d}=\left(\frac{2}{3 L_{s}}\right) v_{d}$ is the system control input, and $\xi_{i d}=\left(\frac{2}{3 L_{s}}\right)\left(-R_{s} i_{d}-\right.$ $\left.\frac{3}{2} L_{s} i_{q} n_{p} \frac{d}{d t} \theta\right)$ is the total disturbance term.

We use the simplified model, in equation (36), to design a proportional-integral (PI) controller to regulate the value of the current $i_{d}$ towards $i_{d}=0$. This controller written in a classical compensation network form is

$$
U_{d}(s)=-\left[k_{1}+\frac{k_{0}}{s}\right] i_{d}(s)
$$

The coefficient $k_{1}$ and $k_{0}$ are design parameters which are computed as following: $k_{0}=\omega_{n}{ }^{2}$ and $k_{1}=2 \zeta \omega_{n}$ to ensure exponential stability of the controller, where $\zeta$ and $\omega_{n}$ must satisfy $\omega_{n}>0$ y $0<\zeta<1$.

In recent works, it has been demonstrated that the well-known proportional integral derivative controller (PID) and flat filter controllers are equivalent to the active disturbance rejection control. See (Sira-Ramirez, Zurita-Bustamante, \& Huang, 2019), (SiraRamírez \& Zurita-Bustamante, On the equivalence between ADRC and Flat Filter based controllers: A frequency domain approach, 2021).

\section{Sinchronization with the electrical grid}

To achieve an adequate connection between the wind turbine and the electrical grid, the electricity generated by the wind turbine must be synchronized with the electricity in the electrical grid. The synchronization is not necessary only to make the connection; both systems need to be synchronized all the time. Therefore, before continuing with the control of the grid side converter, we must know or estimate the phase angle of the electrical grid. Both systems are synchronized via a phase lock loop (PLL), specifically a phase lock loop in the synchronous reference frame (SRF-PLL), which estimates the grid's phase angle. Then, the Park transformation and its inverse employ this estimate. By doing this, the controllers of the grid side converter commute the Back-to-Back converter to generate electric power in phase with the electricity in the grid. Let's suppose that the electrical grid has a cosine based function,

$$
\left[\begin{array}{l}
V g a \\
V g b \\
V g c
\end{array}\right]=\left[\begin{array}{c}
V \cos \left(\theta_{g}\right) \\
V \cos \left(\theta_{g}-\frac{2 \pi}{3}\right) \\
V \cos \left(\theta_{g}+\frac{2 \pi}{3}\right)
\end{array}\right]
$$

Where $\theta_{g}=\omega_{g} t+\phi_{g}, \omega_{g}$ is the grid's base frequency and $\phi_{g}$ is a deviation of the input frequency nominal value. The corresponding grid voltages in the synchronous reference frame are computed using the Clarke and Park transformations:

$$
\left[\begin{array}{l}
V g d \\
V g q \\
V g 0
\end{array}\right]=\kappa\left[\begin{array}{c}
\frac{3}{2} V \cos \left(\theta_{g}-\phi_{p}\right) \\
\frac{3}{2} V \sin \left(\theta_{g}-\phi_{p}\right) \\
0
\end{array}\right]
$$

Where $\phi_{p}$ is the estimate Park's angle. Notice that if the estimate Park's angle coincides with that for the electrical grid (i.e. $\phi_{p}=\theta_{g}$ ), the voltage $V_{g q}=0$. It follows that regulating the voltage $V_{g q}$ towards zero, the electrical grid phase angle can be estimated; this is accomplished via a PI controller, as shown in Figure 6.

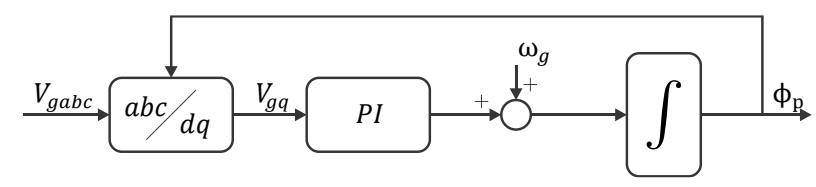

Figure 6 Synchronous reference frame phase lock loop. Source: Made by the author 
The whole scheme is known as a phase lock loop in the synchronous reference frame (SRF-PLL). In the book (Karimi-Ghartemani, 2014), this and other topologies are presented.

\section{DC-link voltage control}

To design the control scheme that regulates the DC-link voltage towards the desired value, consider the simplified model of the equation (24),

$$
\ddot{V}_{c d}=-\frac{3 V_{g d}}{2 L_{f} V_{d c}} V_{i d}+\xi_{c d}=U_{i d}+\xi_{c d}
$$

Where $U_{i d}=-\frac{3 V_{g d}}{2 L_{f} V_{d c}} V_{i d}$ is the control input and the total disturbance term is given by: $\xi_{c d}=-\frac{3 V_{g d}}{2 V_{d c}}\left(-V_{g d}-R_{f} I_{f d}+\omega_{p} L_{f} I_{f q}\right)+\frac{\dot{I}_{r}}{C}-$ $\frac{3 \dot{V}_{g d} I_{f d}}{2 V_{c d}}+\frac{3 V_{g d} I_{d d} \dot{V}_{c d}}{2 V_{c d}^{2}}$

In terms of the tracking error, the simplified system is:

$$
\ddot{e}_{V_{c d}}=e_{U_{i d}}+\xi_{c d}
$$

The DC-link voltage error is $e_{V_{c d}}=$ $V_{c d}-V_{c d}^{*}$ similarly, the control input error is defined as $e_{U_{i d}}=U_{i d}-U_{i d}^{*}$ where $V_{c d}^{*}$ is the desired value of the DC-link voltage and $U_{i d}^{*}=$ $\frac{d^{2}}{d t^{2}} V_{c d}^{*}$ is the nominal control input.

From the error simplified model, we propose the following Flat Filter controller,

$$
U_{i d}(s)=U_{i d}^{*}-\left[\frac{k_{2} s^{2}+k_{1} s+k_{0}}{s\left(s+k_{3}\right)}\right] e_{V_{c d}}(s)
$$

Whose characteristic polynomial is just

$$
s^{4}+k_{3} s^{3}+k_{2} s^{2}+k_{1} s+k_{0}=0
$$

As happened in the previous cases, selecting the values of gain parameters $k_{3}, k_{2}, k_{1} y k_{0}$, such that they constitute a Hurwitz set guarantees exponential stability of the controller. So, the flat Filter parameters in equation (42) are computed as in (32). It's worth mentioning that the values of these two sets of gain parameters are not necessarily the same.
Similar to the equivalence between PID and ADRC, active disturbance rejection control is also equivalent with flat filters under a coprimeness condition between the characteristic polynomials of the controller and that of the observer. So by respecting the separation principle of the observer and controller characteristic polynomials given an ADRC, we can find an equivalent flat filter (Sira-Ramírez \& Zurita-Bustamante, On the equivalence between ADRC and Flat Filter based controllers: A frequency domain approach, 2021), (SiraRamírez, From flatness, GPI observers, GPI control and flat filters to observer-based ADRC., 2018).

\section{Reactive power control}

Following ADRC methodology, the simplified model of equation (25) is,

$$
\dot{Q}=-\frac{3 V_{g d}}{2 L_{f}} V_{i q}+\xi_{Q}=U_{i Q}+\xi_{Q}
$$

Where the control input of the system is $U_{i Q}=-\frac{3 V_{g d}}{2 L_{f}} V_{i q}$ and the total disturbace term is given by $\xi_{Q}=\left(-V_{g q}-R_{f} I_{f q}-\omega_{p} L_{f} I_{f d}\right)-$ $\frac{3}{2} \dot{V}_{g d} I_{f q}$.

Similar to the design of the $i_{d}$ current regulation controller in previous sections, we propose a PI controller to regulate the reactive power $Q$ to the desired value. Once again, the controller in classical compensation network form is:

$$
e_{U_{i q}}(s)=-\left[k_{1}+\frac{k_{0}}{s}\right] e_{Q}(s)
$$

Where the instantaneous reactive power error is $e_{Q}=Q-Q^{*}$ and the control input error is defined as $e_{U_{i q}}=U_{i q}-U_{i q}^{*}$ where $Q^{*}$ is the reactive power desired value. The nominal control input is just $U_{i q}^{*}=\frac{d^{2}}{d t^{2}} Q^{*}$.

The coefficients $k_{1}$ and $k_{0}$ are the design parameters and are computed as: $k_{0}=\omega_{n}{ }^{2}$ and $k_{1}=2 \zeta \omega_{n}$ to be a Hurwitz set and thus guarantee asymptotic stability of the controller, where $\omega_{n}>0$ and $0<\zeta<1$. 


\section{Numerical simulations}

We realized numerical simulations using the software Simulink Matlab to test the performance of the previously proposed controllers. We consider a horizontal directdriven wind turbine based on a permanent magnet synchronous generator with a power capacity of $5 \mathrm{MW}$, whose parameters are in Table 1.

\begin{tabular}{|l|c|r|c|}
\hline Parameter & Symbol & \multicolumn{1}{|l|}{ Value } & \multicolumn{1}{c|}{ Unit } \\
\hline Nominal Power & $P_{w, n o m}$ & 5 & $\mathrm{MW}$ \\
\hline Total inertia & $\mathrm{J}$ & $1 \times 10^{4}$ & $\mathrm{Kg} \cdot \mathrm{m}^{2}$ \\
\hline Blade length & $r_{t}$ & 56 & $\mathrm{~m}$ \\
\hline Wind density & $\mathrm{P}$ & 1.225 & $\mathrm{Kg} \cdot \mathrm{m}^{3}$ \\
\hline Stator resistance & $R_{s}$ & 6.25 & $\mathrm{~m} \Omega$ \\
\hline Stator inductance & $L_{s}$ & 4.229 & $\mathrm{mH}$ \\
\hline $\begin{array}{l}\text { Permanent magnet } \\
\text { flux density }\end{array}$ & $\lambda_{0}$ & 11.1464 & $\mathrm{~Wb}$ \\
\hline Pole pairs number & $n_{p}$ & 75 & - \\
\hline Nominal voltage & $V_{\text {nom }}$ & 0.9 & $\mathrm{kV}$ \\
\hline Nominal angular speed & $\omega_{\text {nom }}$ & 1.447 & $\mathrm{rad} / \mathrm{s}$ \\
\hline
\end{tabular}

Table 1 : Wind turbine parameters

Source: (Aimene, Payman, \& Dakyo, 2014)

For the connection between the wind turbine with the electrical grid, an RL filter is employed. Table 2 presents the parameters of the filter simulated. It is supposed a $0.9 \mathrm{kV}$ at $60 \mathrm{~Hz}$ electrical grid.

\begin{tabular}{|l|c|l|c|}
\hline \multicolumn{1}{|c}{ Parameter } & \multicolumn{1}{c}{ Symbol } & \multicolumn{1}{c|}{ Value } & Unit \\
\hline DC-Link capacitor & $C$ & 40 & $\mu F$ \\
\hline Filter resistance & $R_{f}$ & 0.01 & $m \Omega$ \\
\hline Filter inductance & $L_{f}$ & 0.5 & $m H$ \\
\hline
\end{tabular}

Table 2: Grid Side Converter parameters Source: (Aimene, Payman, \& Dakyo, 2014)

We simulate a realistic wind profile using the library "Aerospace Blockset". The wind profile has an average speed of $11 \mathrm{~m} / \mathrm{s}$, turbulence components, and wind gust characteristics. Effects that usually affect wind turbines. See Figure 7

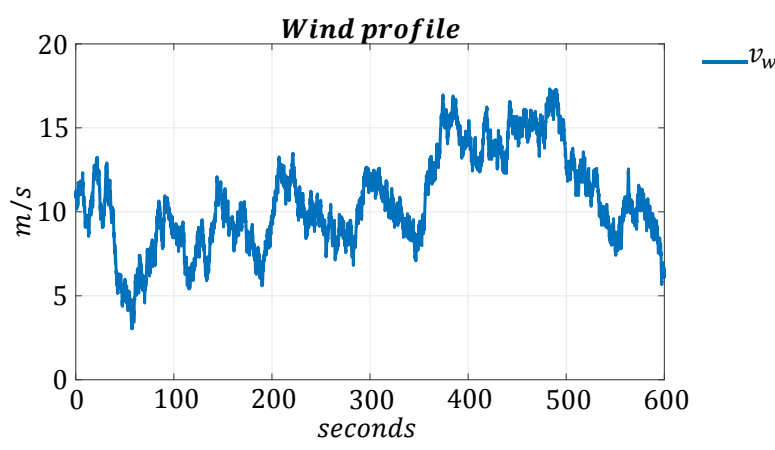

Figure 7 Simulation of a realistic wind profile

Source: Made by the author
Figure 8 shows the performance of the optimum-angular velocity tracking task, the currents $i_{d}$ and $i_{q}$, the control signals, and the angular velocity and current tracking errors. Notice that the controller tracks the optimumangular velocity with a maximum error of $1 \times$ $10^{-3} \mathrm{rad} / \mathrm{s}$.

Therefore, we can affirm that the ADRC controller accurately tracks the reference signal. The current $i_{d}$ is close to zero, with an error of less than $0.01 \mathrm{~A}$. The control objectives are achieved despite the presence of turbulence and wind gust effects.

Regarding the angular velocity graph, it is evident that the optimal velocity never crosses the PMGS nominal angular speed, with a value of $1.447 \mathrm{rad} / \mathrm{s}$. When the wind speed exceeds its nominal value, typically, a PI controller changes the blades' pitch angle $\beta$ to limit the wind energy conversion by reducing the power coefficient $C_{p}$ value. In consequence, the PMSG angular speed is reduced by this effect. A PI controller for a variable speed wind turbine is presented in (Hwas \& Katebi, 2012). Nevertheless, this controller is out of the scope of the current work and is left for further work.
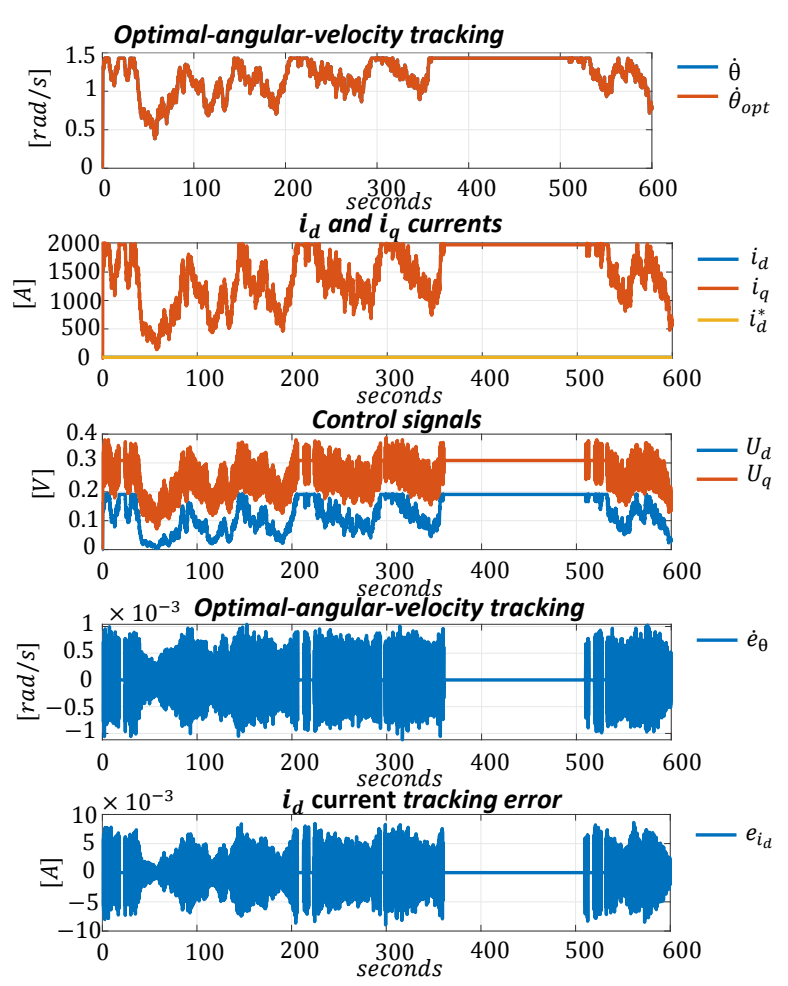

Figure 8 Angular speed, electrical currents, and control inputs for the PMSG

Source: Made by the author 
Figure 9 depicts a zoom at the first ten seconds of the system operation, revealing how the system starts. It's important to say that a smooth trajectory is employed to start the system and avoid subjecting the system to excessive forces and stress. Due to we suppose that the wind turbine is in complete rest at the beginning.
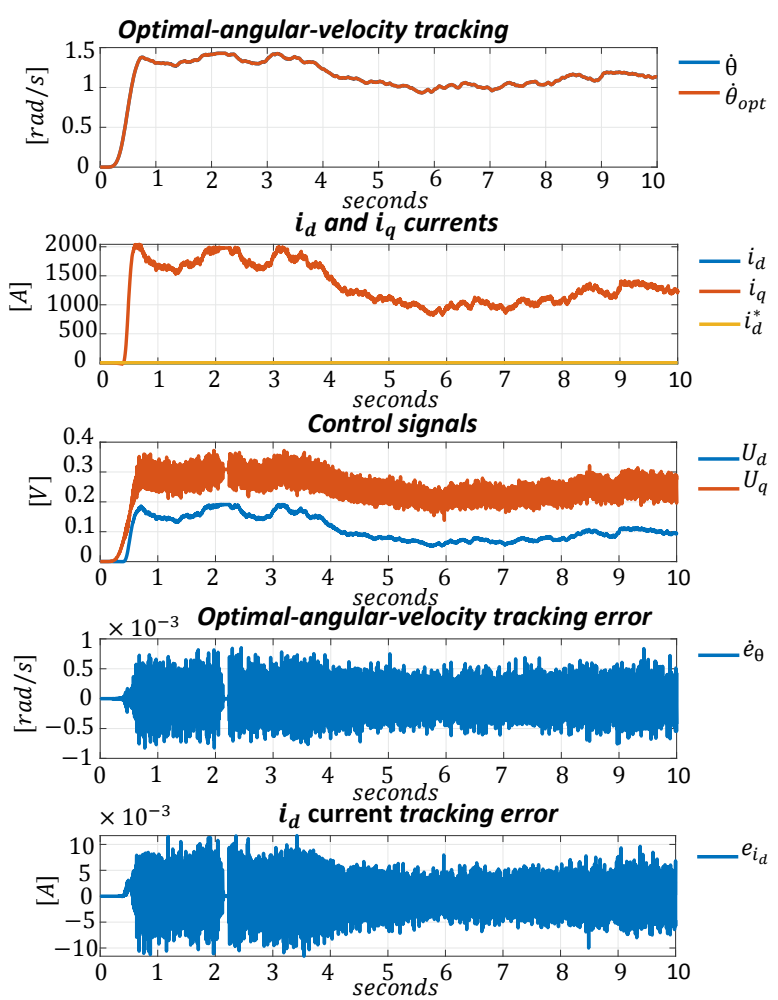

Figure 9 Angular speed and electrical currents during wind turbine startup

Source: Made by the author

Figure 10 presents the graphs obtained for the behavior of the grid side converter. The proposed controller maintains the DC-link voltage in its reference value, $4700 \mathrm{~V}$. Also, the PI controller tracks the desired reference, which represents the reactive power supplied or absorbed from the electrical grid. Notice that once the wind turbine reaches approximately an angular speed of $0.35 \mathrm{rad} / \mathrm{seg}$, the PMSG starts to generate electrical power, and the filter currents start to rise. The magnitude of the filter electric currents varies according to the wind speed.
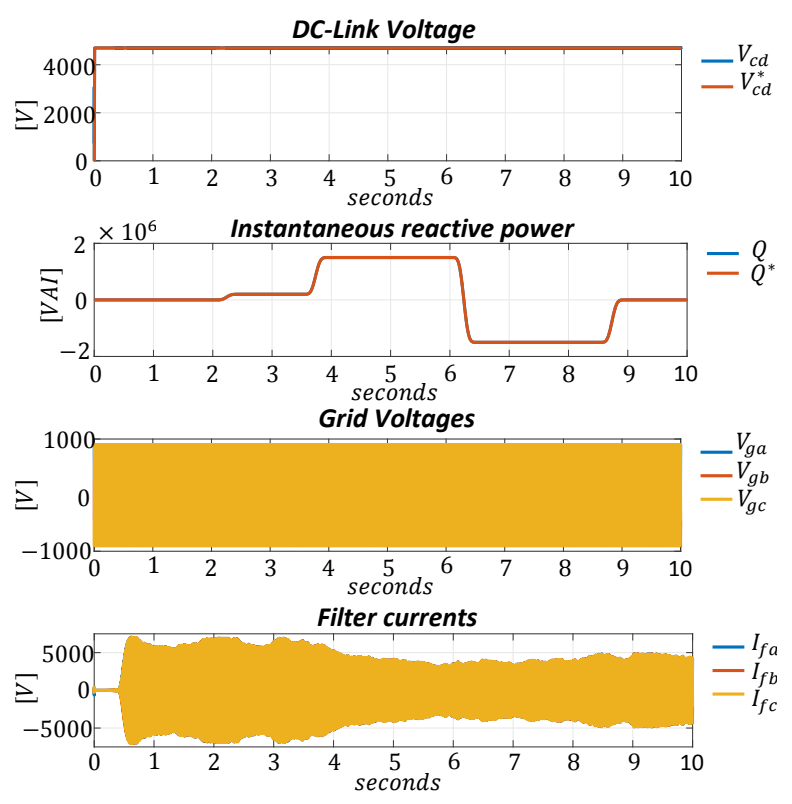

Figure 10: DC-link voltage and instantaneous active and reactive power. Source: Made by the author.

Zooming one more time from $t=1[s]$ to $t=1.1[s]$, see Figure 11 notice the approximately $10[\mathrm{~V}]$ variation in the DC-link voltage. The DC-link voltage is constantly subject to voltage variations due to the repeated charge and discharge of the capacitor, caused by the changes in wind speed, thus the PMSG angular velocity, and the management of the electrical energy supply to the grid.

Despite all the above, the proposed controller achieves a DC-Link voltage so close to the desired reference by the proper commutation of the grid side converter. It is also noticed that the value of the instantaneous reactive power highly approaches its reference value.

Finally, notice that the current supplied to the electrical grid is synchronized and has a 60 $\mathrm{Hz}$ frequency. 

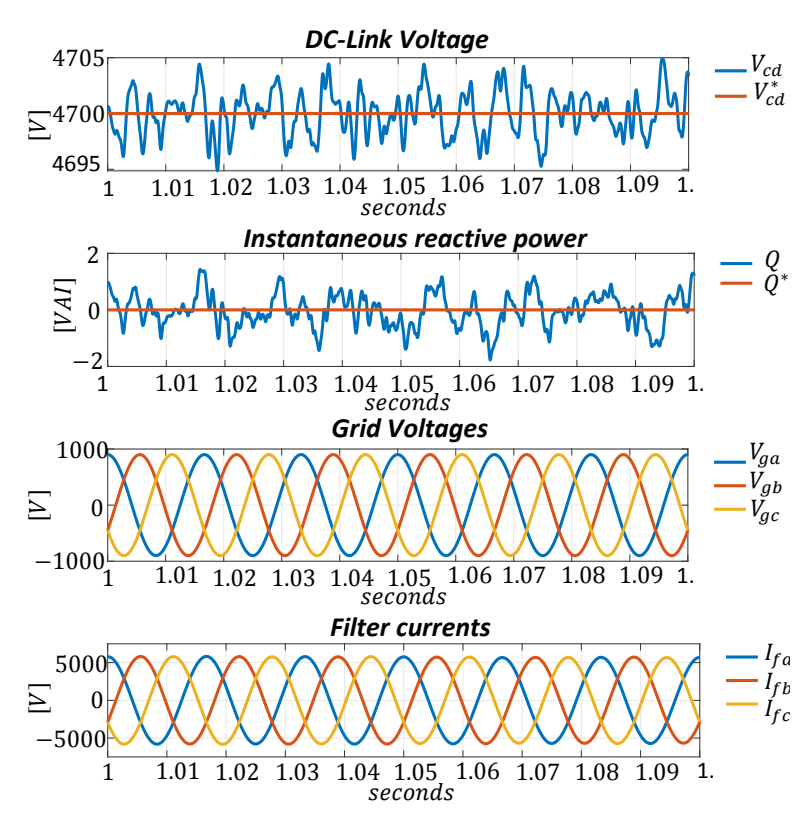

Figure 11: Zoom to grid voltages and filter currents. Source: Made by the autho

\section{Conclusions}

The main objective of this manuscript is to take advantage of the PMSG differential flatness property and employ robust control strategies to solve the MPPT control problem and manage the electricity generated to the electrical grid considering a horizontal axis wind turbine with a PMSG connected to the grid.

The flatness property and the control schemes employed in this work give the advantage of avoiding measuring the complete state of the system also offer a good performance despite unknown dynamics, unknown parameters, and external disturbances. Despite the subsystems that compound the wind turbine interacts with each other, this methodology allows designing control schemes for each system independently.

Numerical simulations show that the active disturbances rejection controller offers good performance, even when the control design is done under a quite simplified model of the system and despite all the disturbances affecting the system and the nonlinearities ignored.

In further work, we pretend to design control schemes to solve the maximum power point tracking without the measurement of the angular position of the permanent magnet synchronous generator and even avoiding the measurement of wind speed to reduce cost or improve the performance of the whole system.

\section{References}

Ackermann, T. (2005). Wind power in power systems. Chichester, UK: John Wiley.

Ackermann, T., \& Söder, L. (2002). An overview of wind energy-status 2002. Renewable and Sustainable Energy Reviews, 67127.

Aimene, M., Payman, A., \& Dakyo, B. (2014). Flatness-based control of a variable-speed windenergy system connected to the grid. Ninth International Conference on Ecological Vehicles and Renewable Energies, (pp. 1-7). Monte-Carlo, Monaco.

Akagi, H., Watanabe, E. H., \& Aredes, M. (2017). Instantaneous power theory and applications to power conditioning. Hoboken, New Jersey: John Wiley \& Sons.

Bianchi, F. D., de Battista, H., \& Mantz, R. J. (2007). Wind Turbine Control Systems. London: Springer-Verlag.

Fliess, M., Lévine, J., Martin, P., \& Rouchon, P. (1992). Sur les systèmes non linéaires différentiellement plats. CR Acad. Sci., (pp. 619624). Paris.

Hwas, A., \& Katebi, R. (2012). Wind Turbine Control Using PI Pitch Angle Controller. IFAC Proceedings Volumes, 241-246.

Karimi-Ghartemani, M. (2014). Enhanced phase-locked loop structures for power and energy applications. John Wiley \& Sons.

Njiri, J., \& Söffker, D. (2016). State-of-the-art in wind turbine control: Trends and challenges. Renewable and Sustainable Energy Reviews, 377-393.

Polinder, H., Ferreira, J. A., Jensen, B. B., Abrahamsen, A. B., Atallah, K., \& McMahon, R. A. (2013). Trends in wind turbine generator systems. IEEE Journal of emerging and selected topics in power electronics, 174-185.

Sira-Ramírez, H. (2018). From flatness, GPI observers, GPI control and flat filters to observer-based ADRC. Control Theory and Technology, 249-260. 
Sira-Ramírez, H., \& Agrawal, S. (2004). Differentially flat systems. Crc Press.

Sira-Ramírez, H., \& Zurita-Bustamante, E. W. (2021). On the equivalence between ADRC and Flat Filter based controllers: A frequency domain approach. Control Engineering Practice.

Sira-Ramírez, H., Luviano-Juárez, A., RamírezNeria, M., \& Zurita-Bustamante, E. W. (2017). Active disturbance rejection control of dynamic systems: a flatness based approach. Elsevier.

Sira-Ramirez, H., Zurita-Bustamante, E. W., \& Huang, C. (2019). Equivalence among flat filters, dirty derivative-based PID controllers, ADRC, and integral reconstructor-based sliding mode control. IEEE Transactions on Control Systems Technology, 1696-1710.

Wu, B., Lang, Y., Zargari, N., \& Kouro, S. (2011). Power Conversion and Control of Wind Energy Systems. John Wiley \& Sons. 